\title{
Myocardial oxygen supply:demand ratio as reference for coronary vasodilatory drug effects in humans
}

\author{
Isabelle Vergroesen, Jasper E Kal, Jos A E Spaan, Harry B Van Wezel
}

\begin{abstract}
Objective-Introduction and measurement of human myocardial oxygen supply:demand ratio as a reference for quantification of coronary microvascular vasodilating drug effects in clinical studies. Myocardial oxygen consumption is the major determinant of coronary blood flow; therefore, the true vasodilating properties of coronary vasodilating drugs that may have an effect on oxygen consumption cannot be correctly assessed from blood flow changes alone.

Design-Prospective, controlled trial.
\end{abstract}

Setting-Academic hospital.

Patients-12 patients with multivessel coronary artery disease (CAD) undergoing coronary artery bypass grafting. Interventions-Cardiac pacing at 30 beats/min above sinus rhythm in awake and anaesthetised patients (fentanyl/pancuronium bromide).

Main outcome measures-Myocardial oxygen supply, defined as coronary sinus blood flow multiplied by arterial oxygen content; myocardial oxygen demand, defined as coronary sinus blood flow multiplied by arteriovenous oxygen content difference. The change in oxygen demand induced by pacing was related to the change in myocardial oxygen supply in awake and anaesthetised patients. This myocardial oxygen supply:demand ratio determined in the reference study was compared with that induced by intravenous and intracoronary drugs (nifedipine, felodipine, urapidil, and sodium nitroprusside) in two pharmacological studies: patients with CAD undergoing cardiac surgery (45 treated with sodium nitroprusside, 27 with nifedipine, and 27 with urapidil to manage arterial blood pressure); and patients with unstable angina (and a similar degree of CAD) undergoing cardiac catheterisation for diagnostic purposes (10 treated with intracoronary nifedipine and 10 with intracoronary felodipine).

Results-When awake, the ratio of pacing induced oxygen supply:demand changes in the 12 reference study patients was $1 \cdot 50$ (95\% confidence intervals (CI), 1.411.58), similar to the $1.45(1.35-1.56)$ measured in the same patients after induction of anaesthesia. Anaesthesia per se did not increase coronary oxygen supply above the expected increase related to demand changes. The only significant change in the oxygen supply:demand ratio was induced by intracoronary bolus administration of nifedipine and felodipine (10.6 (SE 1.9) and $13.9(1.9) \mathrm{ml} / \mathrm{min}$, respectively, above the demand related supply). Conclusions-Quantification of coronary vasoactive properties in relation to the physiological reference ratio between myocardial oxygen supply and demand may be a powerful tool to differentiate between true and apparent coronary vasoactive drugs.

(Heart 1997;78:117-126)

Keywords: coronary circulation; vasodilatation; metabolic flow regulation; vasoactive drugs; pacing

Normal regulation of coronary blood flow is a multifactorial process possibly depending on metabolic, myogenic, neurohumoral, and endothelial responses. ${ }^{1-6}$ The overall effect of these combined responses leads to continuous matching of myocardial oxygen supply and demand..$^{7-9}$ In humans the myocardial oxygen supply:demand ratio should be considered when the effects of coronary vasodilatory stimuli are described. Although there is a wide body of literature dealing with the effect of coronary vasodilators on myocardial blood flow and oxygen consumption, the potential involvement of the normal regulation process of coronary flow is rarely taken into account. ${ }^{1011}$ The purpose of the present study was to redress this inadequacy in the assessment of the capacity of drugs to vasodilate the resistance vessels of the coronary circulation.

\section{Methods}

A physiological reference study gathered data from 12 patients (both awake and anaesthetised) with multivessel coronary artery disease (CAD) undergoing coronary artery bypass surgery. These data were compared with those from 45 anaesthetised patients treated with sodium nitroprusside, 27 anaesthetised patients treated with urapidil, and 27 anaesthetised patients treated with nifedipine. These patients had been studied to evaluate the effectiveness of the drugs in the management of arterial blood pressure during cardiac surgery. ${ }^{12-14}$ They were also compared with a study of awake patients undergoing cardiac catheterisation for diagnostic purposes; 10 treated with intracoronary nifedipine and 10 treated with intracoronary felodipine. ${ }^{15}$ 
PATIENT CHARACTERISTICS

All patients gave informed consent to participate in one of the studies that all had institutional approval. For the physiological reference study and for the drug studies under anaesthesia, the patients with stable coronary artery disease (CAD) were scheduled for elective coronary artery surgery. Excluded from the study were patients with left ventricular end diastolic pressure higher than $18 \mathrm{~mm} \mathrm{Hg}$, left ventricular hypertrophy, ejection fraction less than $45 \%$, atrioventricular conduction defects, main stem stenosis or unstable angina. Patients undergoing additional surgical procedures-for example, valve replacement or aneurysmectomy, were also excluded. In the pharmacological study of awake patients after cardiac catheterisation for diagnostic purposes, patients were confirmed to meet similar criteria of CAD as the other groups. ${ }^{15}$

\section{INSTRUMENTATION}

For patients undergoing surgery, ECG leads were connected and leads II, III, and V5 were continuously monitored (HP Merlin System, Hewlett-Packard, Böblingen, Germany). A wide bore peripheral infusion and a 20 gauge radial artery canula were inserted under local analgesia.

For the awake patients, a triple lumen pulmonary artery catheter (Baxter Health Care Corporation, Irvine, California, USA) and a coronary sinus thermodilution catheter (Wilton-Webster Laboratories, Altadena, California, USA, type CCS-7U-90B) were introduced via the left subclavian vein as described before. ${ }^{121316}$ The absence of right atrial admixture in coronary sinus blood was checked by injection of cold saline in the right atrium, while coronary sinus temperature curves were recorded simultaneously. ${ }^{1718}$ Under fluoroscopy, pacing (via coronary sinus catheter) was practised during 10 to $30 \mathrm{sec}-$ onds to ascertain the stability of the position of the tip of the coronary sinus catheter in relation to the surrounding anatomical structures and fluoroscopic landmarks. In addition, the electrical threshold for pacing was determined. For the measurement of coronary sinus blood flow, normal saline at room temperature was used as indicator and infused into the coronary sinus at a rate of $45 \mathrm{ml} / \mathrm{min}$ via a Mark IV infusion pump (Medrad Technology for People, Pittsburgh, USA). ${ }^{19}$ Infusion rates were verified by timed volume collection and flow calculations reflected the indicator infusion rate used.

\section{ANAESTHESIA TECHNIQUE}

Calcium channel blockers and long acting nitrates were given until the evening before surgery. $\beta$ adrenoreceptor blocking agents were continued until the morning of surgery. Lorazepam 4-5 mg was given for premedication two hours before surgery.

At the start of induction of anaesthesia the patients were pre-oxygenated. Pancuronium bromide $(2 \mathrm{mg}$ ) was given followed by fentanyl $(100 \mu \mathrm{g} / \mathrm{kg})$ injected over five minutes. When the patient became unresponsive to commands an additional $6 \mathrm{mg}$ dose of pancuronium was given, ventilation was assisted and then controlled manually. After intubation of the trachea the lungs were ventilated with air and oxygen $\left(\mathrm{FIO}_{2}=0 \cdot 5\right)$. Ventilation was adjusted to maintain the end-tidal carbon dioxide concentration between $4 \%$ and $4.5 \%$. In the first 15 minutes following induction of anaesthesia $250-500 \mathrm{ml}$ of gelofuscine (Vifor Medical SA, Crisier, Switzerland) was infused to maintain a stable haemodynamic situation. Gelofuscine is a gelatine solution containing (per $500 \mathrm{ml}$ ) $20 \mathrm{~g}$ of modified gelatin, $77 \mathrm{mmol} \mathrm{Na}^{+}, 63 \mathrm{mmol} \mathrm{Cl}^{-}$, pH 7.1-7.7, $279 \mathrm{mOsm} / \mathrm{l}$.

\section{PHYSIOLOGICAL REFERENCE STUDY}

The measurement protocol and data analysis of the reference study are shown in figure 1 . After adequate instrumentation and a resting period of 20 minutes a measurement series was obtained in 12 awake patients. Twenty minutes after induction of anaesthesia and endotracheal intubation, the complete protocol was repeated. Each set of measurements consisted of a steady state recording period of coronary sinus blood flow, arterial blood pressure, pulmonary artery pressure, right atrial pressure, and ECG lead II for 20 seconds. These recordings were stored on a computer disk for off-line analysis. Furthermore, pulmonary capillary wedge pressure and single bolus cardiac outputs were obtained. Cardiac output was calculated as the average of at least three measurements and reported as cardiac index (CI) (cardiac output/body surface area in $1 / \mathrm{min} / \mathrm{m}^{2}$ ). Blood samples from the radial artery and coronary sinus were drawn to determine plasma haemoglobin, partial pressure of oxygen $\left(\mathrm{PO}_{2}\right)$, and oxygen saturation $\left(\mathrm{SatO}_{2}\right)$.

$\mathrm{SatO}_{2}$ was measured by an OSM-II haemoxymeter (Radiometer, Copenhagen) and $\mathrm{PO}_{2}$ by an ABL-III (Radiometer).

Myocardial metabolic indices were calculated according to standard formulae. ${ }^{16}$

$\mathrm{cO}_{2}=2 \cdot 24 \cdot \mathrm{Hb} \cdot \mathrm{SatO}_{2}+0.003 \cdot \mathrm{PO}_{2}(\mathrm{ml}$ $\mathrm{O}_{2} / 100 \mathrm{ml}$ )

$\mathrm{MVO}_{2}=\mathrm{CSBF} \cdot\left(\mathrm{cO}_{2, \mathrm{art}}-\mathrm{cO}_{2, \mathrm{cs}}\right) / 100(\mathrm{ml}$ $\mathrm{O}_{2} / \mathrm{min}$ )

myocardial oxygen supply $=\mathrm{CSBF}$. $\mathrm{cO}_{2, \text { arr }} / 100\left(\mathrm{ml} \mathrm{O}_{2} / \mathrm{min}\right)$

where $\mathrm{CO}_{2}$ is oxygen content, $\mathrm{Hb}$ is plasma haemoglobin, $\mathrm{cO}_{2 \text {,art }}$ is arterial oxygen content, $\mathrm{cO}_{2, \mathrm{cs}}$ is coronary sinus oxygen content, and $\mathrm{MVO}_{2}$ is myocardial oxygen consumption.

PHARMACOLOGICAL STUDIES

In the pharmacological studies in patients undergoing coronary artery bypass grafting (CABG) the protocol consisted of a series of baseline measurements 10 minutes after induction of anaesthesia, followed by onset of continuous infusion of the study drug. Infusion rates of each drug were adjusted to maintain systolic blood pressure between $80 \%$ and $120 \%$ of baseline values. Additional measurements were obtained 10 minutes after the onset of infusion of the study drugs (before surgery started) and after sternotomy when the 


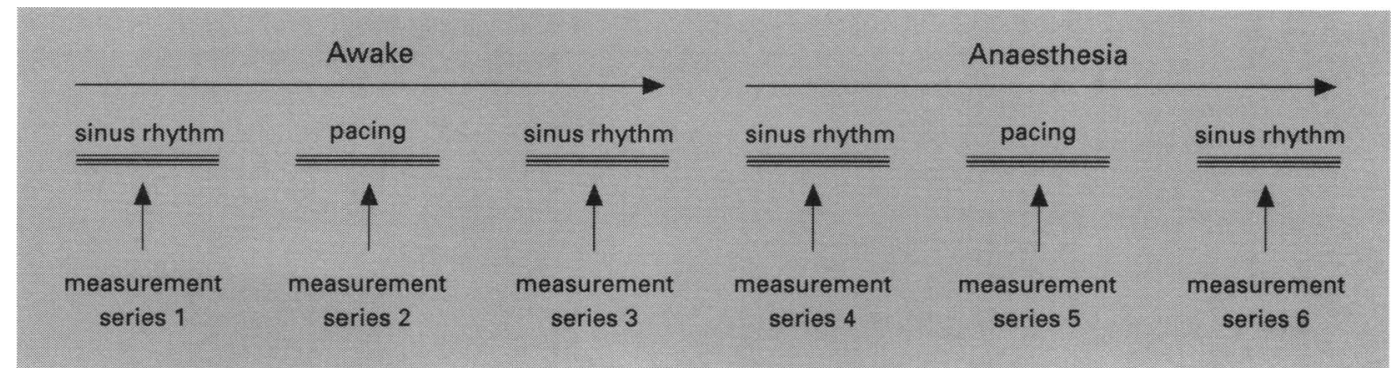

Data analysis and presentation
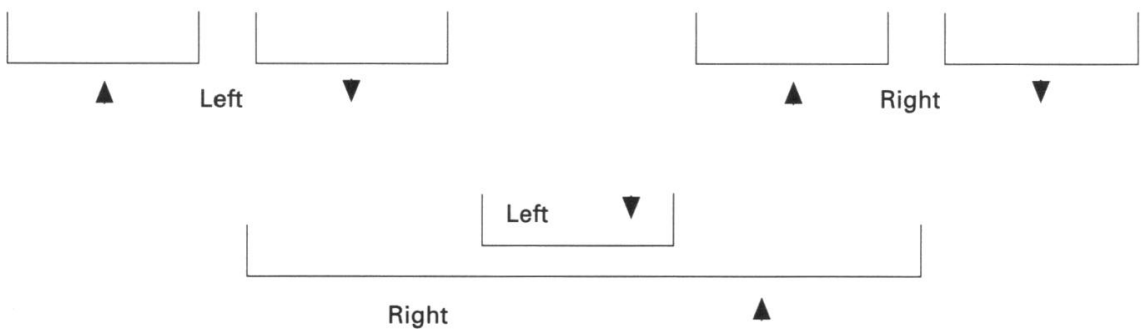

Figure 1 The upper part shows the protocol. Each measurement series includes 20 seconds recording of coronary sinus blood flow, arterial blood pressure, pulmonary artery pressure, right atrial pressure, and ECG lead II, followed by measurement of pulmonary capillary wedge pressure, cardiac output, and withdrawal of arterial and coronary sinus blood samples. Data analysis and presentation: the pacing induced changes in $\mathrm{MVO}_{2}$ and oxygen supply were calculated from the difference between values obtained in measurement series 2 and 1 (awake), and 5 and 4 (anaesthesia). Changes induced by cessation of pacing were calculated from the differences between measurement series 3 and 2 (awake), and 6 and 5 (anaesthesia). The results of this analysis are presented in figure 3. The effect of anaesthesia was calculated by the changes in myocardial oxygen supply and demand between measurement series 4 and 3 (sinus rhythm), and 5 and 2 (pacing). The results of the latter analysis are presented in figure 4.

pericardium was opened, representing maximal surgical stress. The changes in oxygen supply and demand were calculated for both measurement periods (start dose and following sternotomy) in relation to baseline values as for the reference study.

In the pharmacological study in awake patients after cardiac catheterisation for diagnostic purposes, a baseline measurement was obtained just before intracoronary bolus infusion of the study drug. Additional measurements were obtained $1,3,5,7 \cdot 5$, and 10 minutes after the bolus injection. Changes in oxygen demand and supply were measured one minute after bolus injection, when the

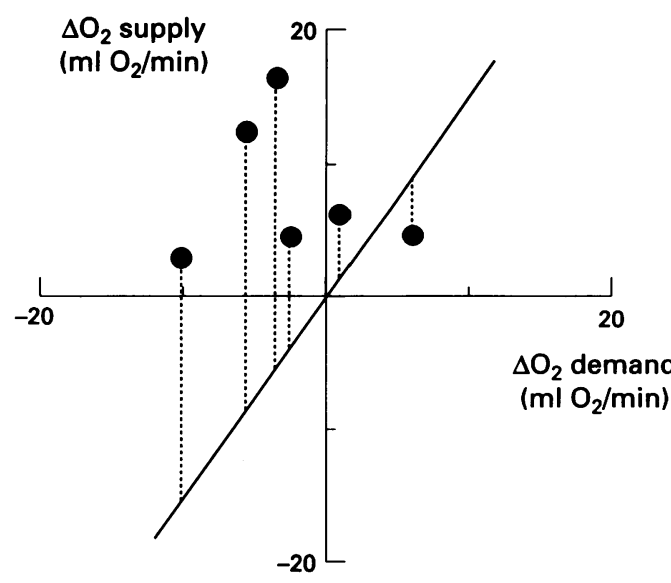

Figure 2 Theoretical demonstration of calculation of coronary microvascular vasodilating potency in a virtual dataset. O, supposed measurements; solid line, human physiological oxygen supply:demand ratio (reference line); dotted lines, individual differences between measured oxygen supply and expected oxygen supply. The mean coronary microvascular vasodilating potency is the mean vertical distance to the reference line according to the dotted lines, where points below the reference line yield negative values and points above the line positive values. change in myocardial oxygen demand was maximal in all cases. ${ }^{15}$

\section{STATISTICAL ANALYSIS}

Data were analysed using paired standard $t$ tests. A value of $P<0.05$ was considered significant. Results are reported as mean (SD) unless stated otherwise. The change in coronary oxygen supply was related to the change in coronary oxygen demand by standard regression analysis. In the physiological reference study using the pacing protocol, a change in myocardial oxygen supply cannot occur without change in myocardial oxygen demand, therefore, this regression line was only calculated without intercept. (Standard formula: $\Delta \mathrm{O}_{2}$ supply $=$ ratio $\cdot \Delta \mathrm{O}_{2}$ demand.) For the quantification of the drug induced effects (including the effect of anaesthesia) on myocardial supply:demand ratios two regression analyses were performed, one with intercept $\left(\Delta \mathrm{O}_{2}\right.$ supply $=$ ratio $\cdot \Delta \mathrm{O}_{2}$ demand $)$ and one without $\left(\Delta \mathrm{O}_{2}\right.$ supply $=$ ratio $\cdot \Delta \mathrm{O}_{2}$ demand + intercept). The estimated ratios (slopes of regression lines) and intercepts are reported with their $95 \%$ confidence intervals (CI) only if the regression analysis resulted in a significant fit.

The coronary microvascular vasodilating potency of each drug was calculated as the mean difference between the expected change in oxygen supply (based on the physiological reference relation and the measured change in oxygen demand) and the actual change in oxygen supply found in each patient. The coronary microvascular vasodilating potency is the mean difference between oxygen supplies found and oxygen supplies expected on the basis of the measured oxygen demand and the reference human oxygen supply:demand ratio 
Table 1 Patient characteristics and clinical data of physiological reference study

\begin{tabular}{|c|c|c|c|c|c|c|c|}
\hline Patient & $\begin{array}{l}\text { Age } \\
\text { (years) }\end{array}$ & Sex & $\begin{array}{l}\text { Height } \\
(\mathrm{cm})\end{array}$ & $\begin{array}{l}\text { Weight } \\
\text { (kg) }\end{array}$ & $\begin{array}{l}\text { Extent of } \\
C A D\end{array}$ & Prior MI & Hypertension \\
\hline 1 & 67 & $\mathbf{M}$ & 168 & 68 & RCA, LAD, LCX & YES & No \\
\hline 2 & 62 & M & 172 & 85 & RCA, LAD, LCX & NO & NO \\
\hline 3 & 66 & $\mathbf{F}$ & 157 & 58 & RCA, LAD & YES & YES \\
\hline 4 & 69 & $\mathbf{M}$ & 175 & 73 & RCA, LAD, LCX & NO & NO \\
\hline 5 & 67 & $\mathbf{M}$ & 176 & 70 & RCA, LAD, LCX & No & YES \\
\hline 6 & 51 & $\mathbf{M}$ & 171 & 94 & RCA, LAD, LCX & No & No \\
\hline 7 & 72 & $\mathbf{M}$ & 182 & 78 & RCA, LAD, LCX & YES & No \\
\hline 8 & 47 & $\mathbf{M}$ & 185 & 86 & RCA, LAD & YES & No \\
\hline 9 & 55 & $\mathbf{M}$ & 174 & 70 & LAD, LCX & YES & No \\
\hline 10 & 71 & $\mathbf{M}$ & 172 & 80 & RCA, LAD, LCX & NO & No \\
\hline 11 & 54 & $\mathbf{M}$ & 172 & 97 & RCA, LAD, LCX & YES & YES \\
\hline & 61 & $M$ & 180 & 86 & RCA, LAD, LCX & NO & NO \\
\hline
\end{tabular}

RCA, right coronary artery; LAD, left anterior descending coronary artery; LCX, left circumflex coronary artery; CAD, coronary artery disease; MI, myocardial infarction.

Table 2 Haemodynamic characteristics of physiological reference study $(n=12)$

\begin{tabular}{|c|c|c|c|c|c|c|}
\hline & \multicolumn{3}{|l|}{ Awake } & \multicolumn{3}{|l|}{ Fentanyl } \\
\hline & Baseline & Pacing & Post pacing & Baseline & Pacing & Post pacing \\
\hline $\begin{array}{l}\mathrm{HR} \\
\text { MAP } \\
\mathrm{RAP} \\
\text { PAP } \\
\text { PCWP } \\
\mathrm{CI} \\
\mathrm{CO}_{2, \text { arr }} \\
\mathrm{CO}_{2, \mathrm{cS}} \\
\mathrm{MVO}_{2} \\
\mathrm{CSBF}\end{array}$ & $\begin{array}{c}61(8) \\
102(21) \\
4 \cdot 8(3 \cdot 5) \\
23(4) \\
13(4) \\
2 \cdot 5(\cdot 7) \\
17 \cdot 9(2 \cdot 2) \\
6 \cdot 3(1 \cdot 3) \\
13(4) \\
108(23)\end{array}$ & $\begin{array}{c}86(6)^{\star} \\
108(22) \\
4 \cdot 2(3 \cdot 7) \\
26(5) \\
11(6) \\
3 \cdot 2(\cdot 6)^{\star} \\
17 \cdot 9(2 \cdot 2) \\
6 \cdot 5(1 \cdot 3) \\
18(7)^{\star} \\
154(35)^{\star}\end{array}$ & $\begin{array}{c}61(7) \\
105(22) \\
5 \cdot 1(3 \cdot 7) \\
24(4) \\
12(5) \\
2 \cdot 7(\cdot 7) \\
17 \cdot 9(2 \cdot 2) \\
6 \cdot 3(1 \cdot 3) \\
13(5) \\
111(24)\end{array}$ & $\begin{array}{l}58(7) \\
79(17) \dagger \\
7 \cdot 3(4 \cdot 2) \dagger \\
20(6) \\
11(3) \\
2 \cdot 4(\cdot 7) \\
19 \cdot 4(2 \cdot 2) \dagger \\
7 \cdot 4(1 \cdot 3) \dagger \\
12(5) \\
99(32) \dagger\end{array}$ & $\begin{array}{c}87(7)^{\star} \\
91(16) \\
6 \cdot 7(4 \cdot 1) \\
22(5) \\
11(3) \\
3 \cdot 1(\cdot 8)^{\star} \\
19 \cdot 2(2 \cdot 2) \\
7 \cdot 2(1 \cdot 1) \\
18(7)^{\star} \\
143(46)^{\star}\end{array}$ & $\begin{array}{c}59(8) \\
80(16) \\
7 \cdot 5(4 \cdot 0) \\
20(5) \\
10(3) \\
2 \cdot 6(\cdot 7) \\
19 \cdot 2(2 \cdot 2) \\
7 \cdot 2(1 \cdot 1) \\
13(60) \\
100(400)\end{array}$ \\
\hline
\end{tabular}

All data are mean (SD); HR, heart rate (beats/min); MAP, mean arterial pressure ( $\mathrm{mm} \mathrm{Hg}$ ); RAP, right atrial pressure $(\mathrm{mm} \mathrm{Hg}) ; \mathrm{PAP}$, mean pulmonary artery pressure $(\mathrm{mm} \mathrm{Hg}) ; \mathrm{PCWP}$, pulmonary capillary wedge pressure $(\mathrm{mm} \mathrm{Hg}) ; \mathrm{CI}$, cardiac
index $\left(1 / \mathrm{min} / \mathrm{m}^{2}\right) ; \mathrm{cO}_{2, \text { art }}$ arterial oxygen content $(\mathrm{ml} / 100 \mathrm{ml}) ; \mathrm{cO}_{2, \mathrm{cs}}$, coronary venous oxygen content $(\mathrm{ml} / 100 \mathrm{ml}) ; \mathrm{MVO}_{2}$,

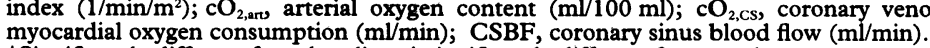

myocardial oxygen consumption $(\mathrm{ml} / \mathrm{min}) ; \mathrm{CSBF}$, coronary sinus blood flow (mifich
$\star$ Significantly different from baseline, + significantly different from awake state.

(fig 2, solid line). Data points below the expected oxygen supply give a negative contribution to the mean coronary microvascular vasodilating potency and data points above the line of expectancy a positive. The physiological reference relation was obtained from the regression line fitted to the pacing induced changes in oxygen supply and demand.

\section{Results}

REFERENCE STUDY

Patient characteristics

The 12 patients participating in the reference study were comparable with respect to age, weight, and height (table 1). Although six patients had suffered a previous myocardial infarction and three had (treated) hypertension, there was no evidence of either impaired left ventricular function and dilatation, or left ventricular hypertrophy. All patients were using long acting nitrates, $\beta$ blockers, and calcium channel blockers for the chronic management of ischaemic heart disease. No patient was excluded from the data analysis during the course of the study for any reason.

Haemodynamic and metabolic characteristics Haemodynamic results obtained in both the awake and anaesthetised condition are reported at baseline, after onset of pacing, and after discontinuation of pacing (table 2). Pacing resulted in a small change in mean arterial pressure in the direction of the heart
Figure 3 Physiological metabolic flow regulation; the effect of pacing $(\boldsymbol{\Delta})$ at 30 beats/min above sinus rhythm, and cessation of pacing $(\nabla)$ on myocardial oxygen supply and demand in patients with coronary artery disease. Left panel, awake; Right panel, after induction of anaesthesia by fentanyl and pancuronium bromide. The lines represent the results of regression analysis to the data presented here and were used as reference in figures 4-7. Details are shown in table 3.

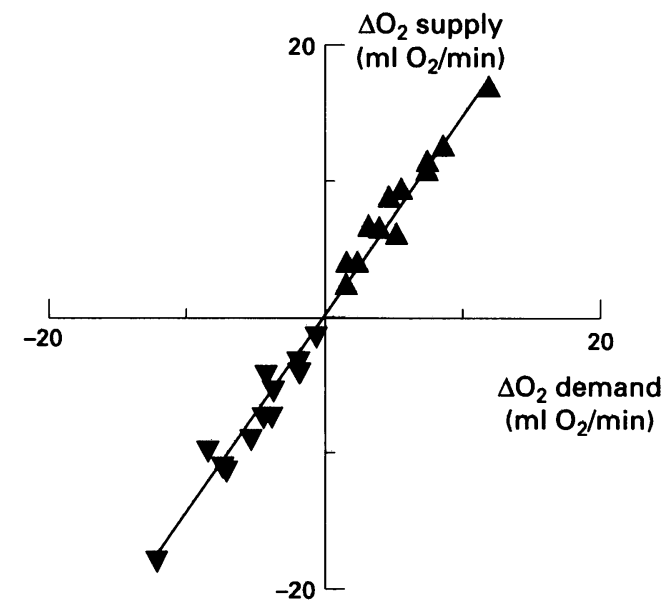

Awake

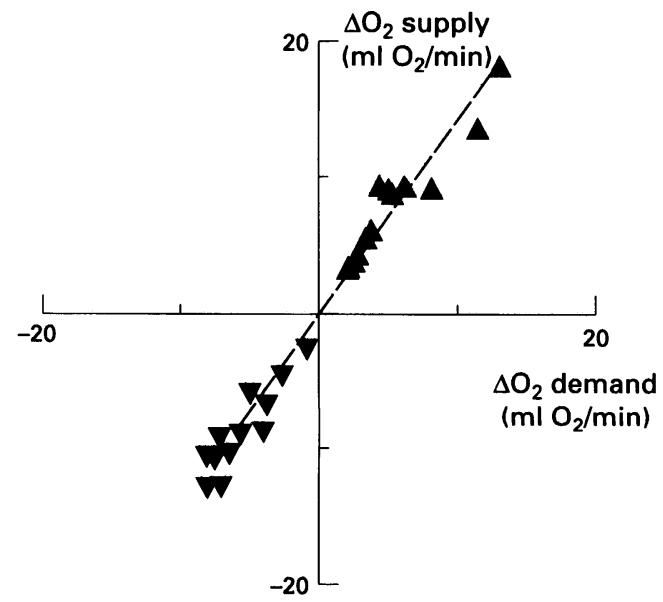

Anaesthesia 
Table 3 Regression analysis: $\Delta \mathrm{O}_{2}$ supply $=$ ratio $\cdot \Delta \mathrm{O}_{2}$ demand

\begin{tabular}{|c|c|c|c|c|c|}
\hline Intervention & $n$ & Ratio & $95 \% C I$ & $r^{2}$ & $\begin{array}{l}\text { Coronary } \\
\text { vasodilatating } \\
\text { potency }\end{array}$ \\
\hline $\begin{array}{l}\text { Pacing, awake } \\
\text { Pacing, anaesthesia } \\
\text { Anaesthesia, sinus rhythm } \\
\text { Anaesthesia, pacing } \\
\text { SNP, start dose (iv) } \\
\text { SNP, sternotomy (iv) } \\
\text { Urapidil, start dose (iv) } \\
\text { Urapidil, sternotomy (iv) } \\
\text { Nifedipine, start dose (iv) } \\
\text { Nifedipine, sternotomy (iv) } \\
\text { Nifedipine, awake (ic) } \\
\text { Felodipine, awake (ic) }\end{array}$ & $\begin{array}{l}24 \\
24 \\
12 \\
12 \\
45 \\
45 \\
27 \\
27 \\
27 \\
27 \\
10 \\
10\end{array}$ & $\begin{array}{l}1.50 \\
1.45 \\
1.41 \\
1.35 \\
1.29 \\
1.50 \\
1.57 \\
1.43 \\
1.37 \\
1.48 \\
\text { NS } \\
\text { NS }\end{array}$ & $\begin{array}{l}1.41-1.58 \\
1.35-1.56 \\
1.29-1.52 \\
1.22-1.48 \\
1.14-1.44 \\
1.26-1.74 \\
1.38-1.75 \\
1.30-1.56 \\
1.08-1.65 \\
1 \cdot 24-1.73 \\
\text { NS } \\
\text { NS }\end{array}$ & $\begin{array}{l}0.98 \\
0.97 \\
0.93 \\
0.97 \\
0 \cdot 87 \\
0 \cdot 72 \\
0.90 \\
0.92 \\
0.73 \\
0.41 \\
\text { NS } \\
\text { NS }\end{array}$ & $\begin{array}{c}0.05(1.20) \\
-0.25(1.35) \\
0.35(1.26) \\
0.69(1.40) \\
0.55(1.47)^{\star} \\
1.78(2.75)^{\star} \\
0.38(1.50) \\
0.85(2.50) \\
0.35(2.25) \\
2.45(5.12)^{\star} \\
10.57(5.87)^{\star} \\
13.85(5.96)^{\star}\end{array}$ \\
\hline
\end{tabular}

Coronary microvascular vasodilating potency $\left(\mathrm{mlO}_{2} / \mathrm{min}\right)$ is calculated as explained in figure 2, presented as mean (SD). All ratio presented were significantly different from zero.

$95 \%$ CI, 95\% confidence interval; $r^{2}$, regression coefficient; $n$, number of observations used to estimate the regression lines presented in tables 3 and 4; SNP, sodium nitroprusside; iv, intravenous; ic, intracoronary; NS, no significant fit.

$\star$ Significantly different from zero.

rate change; during anaesthesia changes in mean arterial pressure were significantly larger compared with the awake state $(12 \mathrm{~mm} \mathrm{Hg} v$ $6 \mathrm{~mm} \mathrm{Hg}$ ). Similarly, the discontinuation of pacing resulted in a blood pressure decrease of $3 \mathrm{~mm} \mathrm{Hg}$ in the awake state, and a blood pressure decrease of $11 \mathrm{~mm} \mathrm{Hg}$ in the anaesthetised state. Compared with the awake situation, mean arterial pressure decreased in all patients significantly after induction of anaesthesia.

Right atrial pressure, pulmonary artery pressure, and pulmonary capillary wedge pressure did not change significantly during the study. CI increased significantly as a result of pacing in both awake and anaesthetised patients.

Arterial and coronary sinus oxygen content $\left(\mathrm{cO}_{2, \text { art }}\right.$ and $\left.\mathrm{cO}_{2, \mathrm{cs}}\right)$, and oxygen supply and demand were calculated at baseline, during pacing (after coronary sinus blood flow had reached a steady state), and after cessation of pacing. In awake and anaesthetised patients, $\mathrm{cO}_{2, \mathrm{cs}}$ did not change in response to heart rate changes, although $\mathrm{cO}_{2, \mathrm{cs}}$ increased $1.1 \mathrm{ml} / \mathrm{ml}$ $(P<0.05)$ and $\mathrm{cO}_{2 \text {,art }}$ increased $1.5 \mathrm{ml} / \mathrm{ml}$ after induction of anaesthesia because of ventilation of the patient. $\mathrm{MVO}_{2}$ increased significantly during pacing and this change was similar in both the awake and anaesthetised state.

Figure 4 Effect of anaesthesia on myocardial oxygen supply and demand in patients with coronary artery disease Left panel, at sinus rhythm; Right panel, during pacing at 30 beats/min above baseline. The lines presented in these figures are the regression lines of the physiological reference data obtained reference data obtained figure 3 (lefi panel). Results of regression analysis of the data and the calculated coronary microvascular vasodilating potency relative to the line shown are presented in table 3.

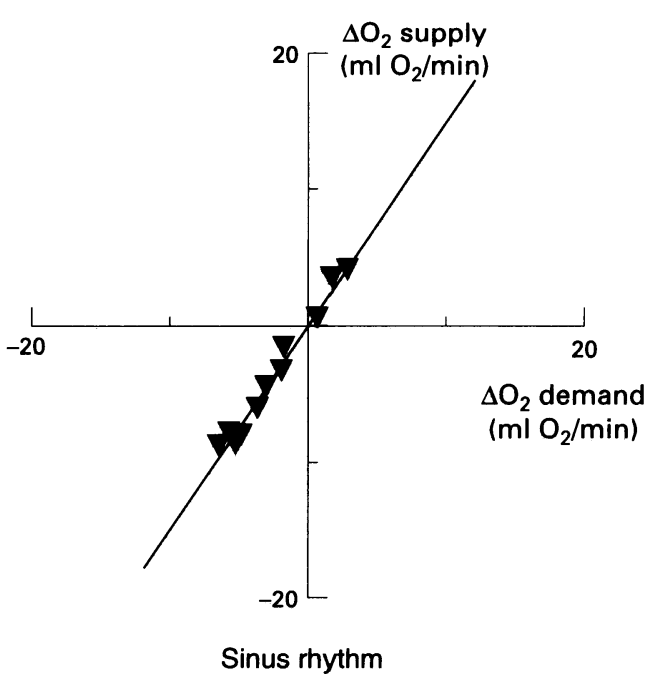

MYOCARDIAL SUPPLY:DEMAND RATIOS

Reference study

Figure 3 shows the pacing induced change in oxygen demand related to the subsequent change in oxygen supply, awake and after induction of anaesthesia. In each patient (both awake and anaesthetised) two supply:demand ratios are shown in each plot, one depicting the effect of pacing versus sinus rhythm, and the second showing the effect of cessation of pacing. The regression lines calculated for both conditions were not significantly different: awake, $\Delta \mathrm{O}_{2}$ supply $=1 \cdot 50 \cdot \Delta \mathrm{MVO}_{2}(95 \%$ CI, 1.41-1.59); anaesthetised, $\Delta \mathrm{O}_{2}$ supply = $1.45 \cdot \Delta \mathrm{MVO}_{2}(1 \cdot 35-1 \cdot 56)$ (table 3 ). The coronary microvascular vasodilating potencies calculated for the pacing induced results give an impression of the natural variation that may be expected in data of this kind.

Figure 4 shows the effect of anaesthesia induced changes in myocardial oxygen demand in relation to the pacing induced regression line in the awake condition (solid line, identical to solid line in figure 3 , left panel). Compared with the awake situation, $\mathrm{MVO}_{2}$ is significantly reduced by anaesthesia (table 2); however, this is associated with a matching decrease in coronary oxygen supply $(r=0.96)$. The calculated regression line is characterised as $\Delta \mathrm{O}_{2}$ supply $=1.41$. 
A
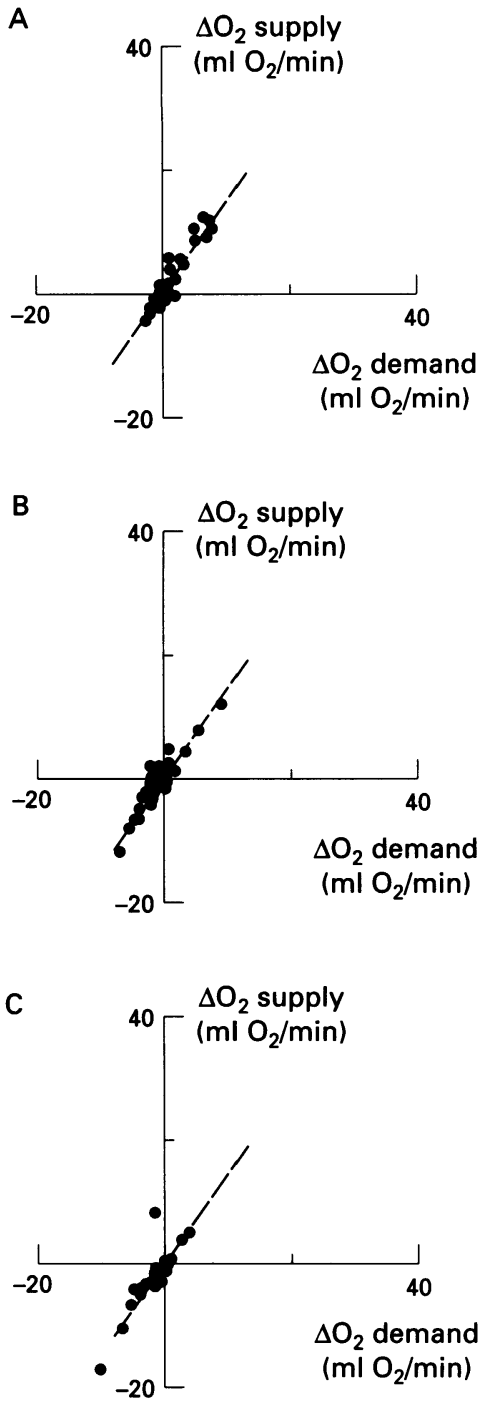

Start dose
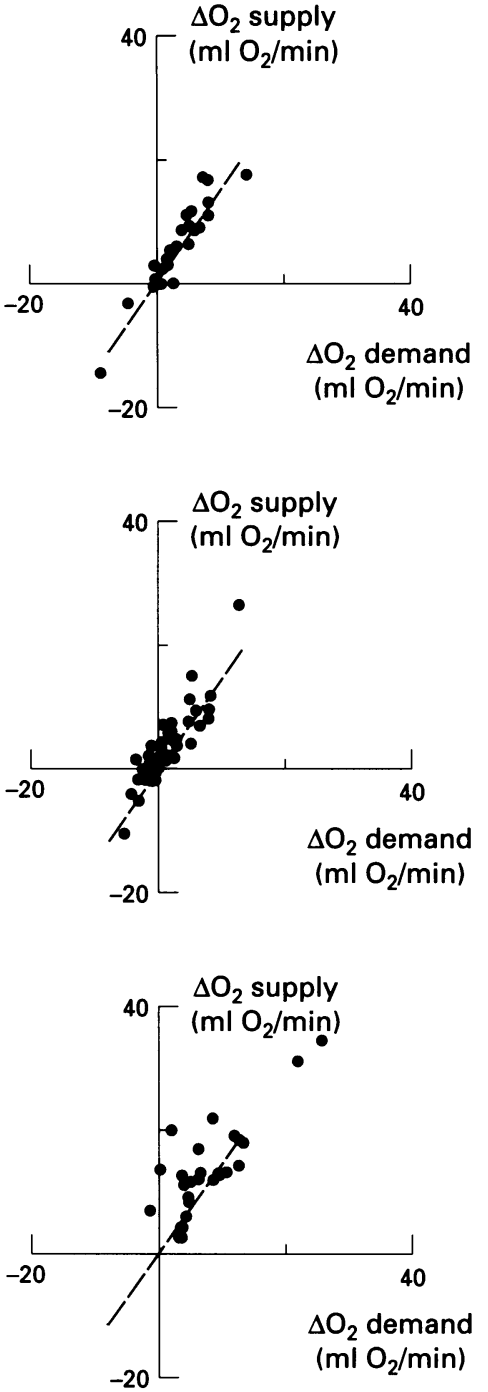

Sternotomy

Figure 5 Effects of potentially vasoactive drugs $(A)$ urapidil, $(B)$ sodium nitroprusside, and $(C)$ nifedipine administered intravenously, on myocardial oxygen supply and demand in anaesthetised patients with coronary artery disease. Left panels, 10 minutes after start of drug infusion before surgery was started; Right panels, after sternotomy, while drugs are infused at a dose sufficient to keep arterial blood pressure between $80 \%$ and $120 \%$ of preinfusion values. Dashed lines in each panel represent the regression line of the physiological reference data shown in figure 3 (right panel) obtained during anaesthesia and were not fitted to the data shown in this figure. These lines were used as reference to calculate the coronary microvascular vasodilating potency of each drug. Results of the regression analysis of the data shown in this figure are presented in tables 3 and 4.

$\Delta \mathrm{O}_{2}$ demand $(95 \% \mathrm{CI}, 1 \cdot 29-1 \cdot 52)$. There was no significant intercept and the regression lines calculated at baseline heart rate and during pacing were not significantly different (table 3 ). The coronary microvascular vasodilating potency of anaesthesia was not significantly different from zero.

Pharmacological studies

The changes in myocardial oxygen demand and supply measured during infusion of urapidil, sodium nitroprusside, and nifedipine are presented in figure 5 for individual patients during anaesthesia. In all panels, the dashed lines represent the physiological supply:demand ratio obtained by pacing during anaesthesia in the physiological reference study (fig 3 ).

Left panels of figure 5 show the effect of a start dose of the different study drugs compared with baseline values. Mean oxygen supply in the control condition was 21 (6) $\mathrm{ml} / \mathrm{min}$. There was a small but significant mean difference in oxygen supply for sodium nitroprusside in relation to the oxygen supply based on the dashed line in figure 5 of $0.55 \mathrm{ml} / \mathrm{min}$ (SE 0.21 ). For both urapidil and nifedipine the coronary microvascular vasodilating potency was not significantly different from zero under these conditions.

The results of regression analysis of these data are presented with (table 3 ) and without (table 4) intercept. Sodium nitroprusside, urapidil, or intravenous nifedipine did not change the ratio between myocardial oxygen supply and demand significantly, compared with the physiological ratio obtained by pacing during anaesthesia (table 3). There was no significant increase in coronary oxygen supply, without change in myocardial oxygen demand, for any of the drugs studied at start dose; therefore, so no significant intercept was found (table 4).

Right panels of figure 5 show the effect of urapidil, sodium nitroprusside, and nifedipine on myocardial oxygen supply and demand at higher infusion rates after sternotomy and opening of the pericardium. Infusion rates were adjusted to keep mean arterial pressure between $120 \%$ and $80 \%$ of baseline values. The mean (SD) coronary microvascular vasodilating potency was calculated and was significant for sodium nitroprusside $(1.78(2.75) \mathrm{ml} /$ $\mathrm{min})$ and nifedipine $(2 \cdot 45(5 \cdot 12) \mathrm{ml} / \mathrm{min})$ but not for urapidil.

Table 4 shows that regression analysis of the effect of sodium nitroprusside and nifedipine revealed a small but significant intercept, indicating an increase in coronary oxygen supply independent of myocardial oxygen demand. However, for nifedipine only, the oxygen supply:demand ratio was significantly decreased, using regression analysis with intercept estimation. All effects of nifedipine (significant coronary microvascular vasodilating potency, significant intercept with the oxygen supply axis, and decreased supply:demand ratio)

Table 4 Regression analysis: $\Delta \mathrm{O}_{2}$ supply $=$ ratio $\cdot \Delta \mathrm{O}_{2}$ demand + intercept

\begin{tabular}{|c|c|c|c|c|c|c|}
\hline Intervention & $n$ & Ratio & $\begin{array}{l}95 \% \text { CI } \\
\text { of ratio }\end{array}$ & Intercept & $\begin{array}{l}95 \% \text { CI of } \\
\text { intercept }\end{array}$ & $r^{2}$ \\
\hline $\begin{array}{l}\text { Anaesthesia, sinus rhythm } \\
\text { Anaesthesia, pacing } \\
\text { SNP, start dose (iv) } \\
\text { SNP, sternotomy (iv) } \\
\text { Urapidil, start dose (iv) } \\
\text { Urapidil, sternotomy (iv) } \\
\text { Nifedipine, start dose (iv) } \\
\text { Nifedipine, sternotomy (iv) }\end{array}$ & $\begin{array}{l}12 \\
12 \\
45 \\
45 \\
27 \\
27 \\
27 \\
27\end{array}$ & $\begin{array}{l}1.53 \\
1.36 \\
1.33 \\
1.40 \\
1.53 \\
1.34 \\
1.41 \\
1.01 \dagger \ddagger\end{array}$ & $\begin{array}{l}1 \cdot 34-1 \cdot 73 \\
1 \cdot 17-1.54 \\
1 \cdot 18-1.49 \\
1 \cdot 19-1.60 \\
1 \cdot 33-1.74 \\
1 \cdot 20-1.49 \\
1 \cdot 07-1.76 \\
0.70-1.32\end{array}$ & $\begin{array}{l}0 \cdot 64 \\
0.07 \\
0 \cdot 45 \\
1 \cdot 83^{\star} \\
0 \cdot 25 \\
1.31 \\
0.28 \\
5 \cdot 73^{\star}\end{array}$ & $\begin{array}{r}-0.16-1.44 \\
-1.17-1.31 \\
-0.01-0.89 \\
1.01-2.65 \\
-0.45-0.96 \\
-0.03-2.46 \\
-0.85-1.41 \\
2.75-8.7\end{array}$ & $\begin{array}{l}0.94 \\
0.97 \\
0.88 \\
0.81 \\
0.90 \\
0.94 \\
0.74 \\
0.64\end{array}$ \\
\hline
\end{tabular}

All ratios presented were significantly different from zero. All intercepts were on the myocardial oxygen supply axis in $\mathrm{mlO} / 2 \mathrm{~min}$. $95 \%$ CI, 95\% confidence interval; $\mathrm{r}^{2}$, regression coefficient; SNP, sodium nitroprusside.

*Significantly different from zero; tsignificantly different from regression without intercept; $\ddagger$ significantly different from the reference regression obtained under similar conditions. 


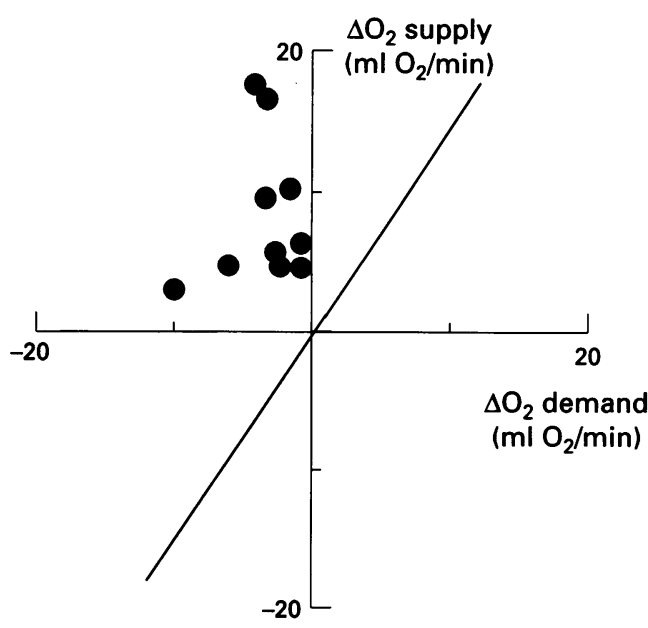

Felodipine

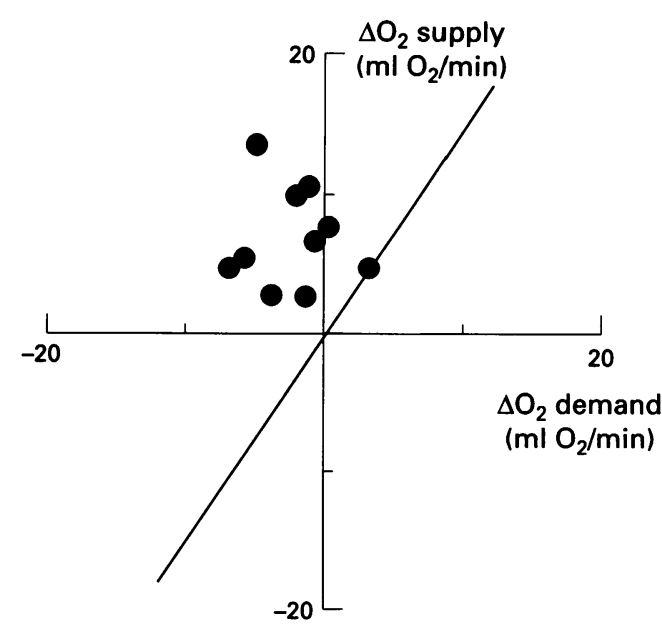

Nifedipine

Figure 6 Effect of intracoronary bolus infusion of felodipine or nifedipine on myocardial oxygen supply and demand in awake patients with coronary artery disease one minute after bolus administration. Left panel, effect of felodipine bolus injection of $0.1 \mathrm{mg}$. Right panel, effect of nifedipine bolus injection of $0.2 \mathrm{mg}$. The solid lines represent the regression line to the physiological reference data obtained in awake patients and presented in figure 3 and was used to calculate the coronary microvascular vasodilating potency of these drugs under these conditions (see table 3).

resulted from an increase in myocardial oxygen supply larger than expected from the physiological supply:demand ratio (dashed line) in only six of 27 patients.

Figure 6 shows the changes in coronary oxygen supply induced by intracoronary bolus injection of felodipine or nifedipine in awake patients after cardiac catheterisation for diagnostic purposes in relation to the concomitantly induced changes in myocardial oxygen demand. The solid lines represent the physiological supply:demand ratio obtained by pacing in the awake patients in the physiological reference study and was used as reference for the calculation of the coronary microvascular vasodilating potency of these drugs under these conditions.

Regression analysis of the changes in oxygen supply to the induced changes in oxygen demand did not yield a significant correlation with or without intercept for either intracoronary felodipine or intracoronary nifedipine.

For nifedipine nine of 10 patients, and for felodipine all 10 patients showed an increase in oxygen supply compared with the expected physiological values (solid line). The coronary microvascular vasodilating potency was 13.85 (SE 1.92 ) $\mathrm{ml} / \mathrm{min}$ for felodipine and 10.57 $(1.89) \mathrm{ml} / \mathrm{min}$ for nifedipine. Both coronary microvascular vasodilating potencies were significantly different from zero and indicate substantial changes in oxygen supply. (Mean (SD) baseline oxygen supply was $22 \cdot 7$ (4.3) $\mathrm{ml} / \mathrm{min}$ for intracoronary nifedipine and $21.7(6 \cdot 3)$ for intracoronary felodipine, both were not significantly different from each other or from the baseline condition in the awake patients of the reference study.)

\section{Discussion}

By establishing the linear relation between myocardial oxygen supply and demand by pacing, the effect of putative vasodilating drugs can be divided between those in which this relation is unaffected (urapidil and sodium nitroprusside) and those which increase the oxygen supply more than expected (felodipine and intracoronary nifedipine). We interpreted the latter effect as a true opening of the resistance vessels of the coronary circulation. The former drugs may dilate the proximal epicardial vessels or the coronary veins, but not the resistance vessels that determine coronary blood flow and thus oxygen supply. Any effect of these drugs on oxygen supply results from the concomitant effect on metabolic rate-that is, myocardial oxygen consumption or oxygen demand.

The aim of the present study was to quantify the physiological response of the coronary flow regulation process to pacing induced changes in myocardial oxygen demand. These data were used to describe the effect of vasoactive compounds on the coronary circulation in relation to this physiological regulation process, as these drugs may have separate effects on $\mathrm{MVO}_{2}$. As the effects of these coronary vasoactive drugs were previously studied in awake and anaesthetised patients, we had to determine the possible effect of anaesthesia on the oxygen supply:demand ratio.

The results indicate that the ratio between pacing induced changes in myocardial oxygen supply and demand was $1.50(0.1)$ in awake patients with CAD and 1.45 (0.1) after induction of anaesthesia by fentanyl/pancuronium bromide; therefore, this type of anaesthesia does not seem to affect the physiological coronary metabolic regulation at steady state.

Subsequently it was shown that vasoactivity of drugs was judged differently compared with normal physiological regulation of coronary blood flow. Intravenous administration of sodium nitroprusside, urapidil, and nifedipine showed rather similar behaviour, compared with the regression line obtained during pacing (fig 5). In the majority of patients studied, the induced changes in myocardial oxygen supply were related to changes in myocardial 

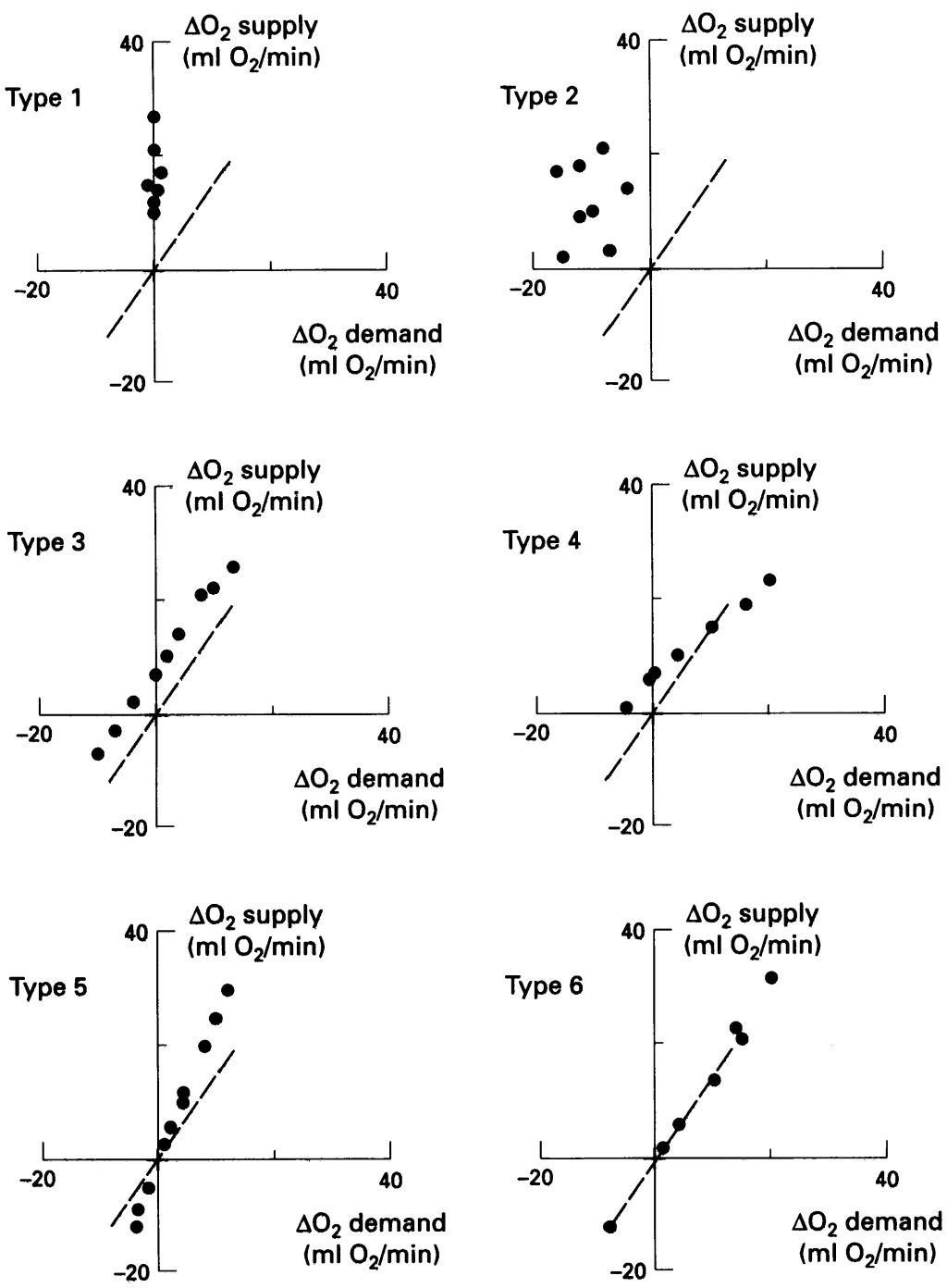

Figure 7 Illustration of the potential of this new analysis. Theoretical vasodilator effects (6) are presented in relation to physiological flow regulation (dotted line in each panel). All panels show an average increase in myocardial oxygen supply as result of drug infusion; however, with the present analysis not all drugs will be deemed coronary infusion; however, with the present analysis not all drugs will be deemed coronary
microvascular vasodilating drugs. Type 1: classic coronary vasodilator affects only coronary oxygen supply and not myocardial oxygen demand. The mean change in oxygen supply will be equal to the mean vasodilating potency of this type of drug. Type 2: coronary vasodilator underestimated by its change in oxygen supply alone. The induced reduction in oxygen demand enhances the vasodilating potency of this type of drug. Type 3: coronary vasodilator characterised by a consistent moderate increase in coronary oxygen supply above the expected physiological supply. Coronary microvascular vasodilating potency and intercept of regression line are equally effective in quantifying its action. The ratio of oxygen supply and demand is unchanged. Type 4: this coronary vasodilator does not yield the same result in each patient. The intercept of the regression line indicates vasodilating the same ribilities at zero change in oxygen demand, but the ratio decreases compared with the physiological line. The coronary microvascular vasodilating potency will reflect the average change in myocardial oxygen supply at the actual changes in myocardial oxygen demand. Type 5: this type of vasodilator shows an increased oxygen supply relative to the physiologically expected supply if myocardial oxygen demand is increased. At a decreased oxygen demand a larger decrease in supply is expected as well. The intercept of the regression line would be equal to zero, but the ratio will increase. The coronary microvascular vasodilating potency may be significantly greater than zero depending on the change in $\mathrm{MVO}_{2}$. Type 6: this drug is not a true vasodilator. The increase in myocardial oxygen supply can be fully explained by the physiological coronary flow regulation. The range of oxygen supply and demand changes shown here is only larger than induced by pacing in the reference study.

oxygen demand. Only a small additional increase in coronary oxygen supply could be attributed to the administration of nifedipine and sodium nitroprusside, but not urapidil. In contrast, intracoronary administration of nifedipine or felodipine showed marked vasodilatation in spite of the decrease in $\mathrm{MVO}_{2}$. This was probably caused by the very high local concentration of nifedipine and felodipine in the coronary vascular wall and the myocardium. In addition, the intracoronary route of bolus administration is not associated with baroreflex mediated sympathetic activation, as is the case with intravenous administration of vasodilators.

PHYSIOLOGY OF CORONARY FLOW REGULATION Coronary flow is determined by myocardial oxygen consumption and coronary perfusion pressure. ${ }^{920}$ These parameters may vary continuously over time; therefore, coronary vascular resistance is adjusted in a continuous dynamic process. This process is mediated by several mechanisms including myogenic, metabolic, neurohumoral, and endothelial responses. The relative influence of each separate response on the overall regulation process is unknown. ${ }^{2021}$

It is well documented that myocardial oxygen supply and demand are tightly coupled so that each change in demand is matched by a corresponding change in supply. ${ }^{79}$ This phenomenon is the result of physiological coronary flow regulation and, in the case of drug administration, this should not be referred to as drug induced vasodilatation or vasoconstriction. We propose to reserve the term "true vasodilatation" for increases in coronary blood flow above the physiological regulation level. This implies that the physiological coronary flow regulation should be known and used as a reference when potential vasodilating agents are studied.

In humans, this physiological regulation process has not been studied extensively. In 1972, Kitamura et al measured coronary blood flow and $\mathrm{MVO}_{2}$ in awake humans (young, male volunteers) during rest and at several levels of exercise. ${ }^{22}$ From the average data the myocardial supply:demand ratio was estimated to be approximately 1.4 . In 1978 Mohrman and Feigl used myocardial supply:demand ratios to characterise the effect of $\alpha$ adrenoreceptor blockade on coronary flow regulation in dogs. ${ }^{8}$ They found a baseline ratio of 0.85 and vasodilatation caused by $\alpha$ adrenoreceptor blockade increased this ratio to $1 \cdot 23$. In 1987, Vergroesen et al reported a myocardial oxygen supply:demand ratio of 1.4 (SE 0.2$)$ in dogs and $1.5(0.2)$ in goats with and without a separate coronary perfusion system. ${ }^{9}$ The discrepancy between the results reported by Mohrman and Feigl, and Vergroesen et al s study is possibly because of differences in the stimulus used to increase $\mathrm{MVO}_{2}$. However, the data of Vergroesen et al and Kitamura et al are in good agreement with the present findings in patients with $\mathrm{CAD}$ (figs 3 and 4 , table 3 ).

USE OF $\triangle \mathrm{O}_{2}$ SUPPLY: $\triangle \mathrm{O}_{2}$ DEMAND RATIO TO EVALUATE VASODILATING PROPERTIES OF DRUGS

A large number of peripheral and coronary arterial vasodilators are currently available for the management of hypertension and ischaemic heart disease. As in most studies describing coronary pharmacodynamic effects only mean changes in coronary blood flow and 
$\mathrm{MVO}_{2}$ are reported (as was done previously with the present data, ${ }^{121315}$ ), the relative vasodilating potency of these different agents is not well defined. A number of parameters that can be used to differentiate between the effects of coronary vasodilators are shown in table 3. These include: the ratio of myocardial oxygen supply and demand at different infusion rates; the intercept with the $\mathrm{Y}$ axis (supply axis); and intrinsic coronary microvascular vasodilating potency, defined as the mean difference between the measured increase in oxygen supply and the expected increase in oxygen supply calculated from the reference supply:demand ratio.

Figure 7 shows the theoretical effects of putative coronary vasodilators on myocardial oxygen supply in relation to the physiological reference supply:demand ratio as measured in the present study. Six different types of drugs are shown that would have been deemed coronary vasodilators according to current clinical practice, but with this new method more differentiation is made.

Comparing theoretical effects of potential coronary vasodilators (fig 7) with the data presented in figures 5 and 6 , we see that the relation between changes in oxygen supply and demand calculated on the basis of the physiological reference study in anaesthetised patients (dashed lines in figure 5) predicted the expected changes in coronary oxygen supply to a very large extent for urapidil and nifedipine at low starting dose (type 6 vasodilatation, fig 7). Only a few patients treated with high dose intravenous nifedipine had significant vasodilatation; therefore, nifedipine is a type 4 vasodilator as shown from the regression line fit with intercept estimation presented in table 4. Sodium nitroprusside appeared to induce a small but consistent upwards shift of the oxygen supply:demand ratio, apparent in the small but significant coronary microvascular vasodilating potency (type 3 vasodilator). The fact that the coronary microvascular vasodilating potency for sodium nitroprusside was significantly different from zero shows that this new method of quantification is highly sensitive. Clinical significance of this small but consistent improvement has yet to be shown. However, the majority of patients treated with sodium nitroprusside showed very little change in either oxygen supply or oxygen demand. Measurement of the vasodilating properties of these drugs by the percentage increases in oxygen supply alone would have overestimated the vasodilating properties of urapidil in both awake and anaesthetised patients, and nifedipine at high dose intravenous infusion.

Figure 6 shows the strength of this analysis. The increase in oxygen supply induced by intracoronary administration of nifedipine and felodipine relative to the reference curve is much larger then the change in oxygen supply per se (type 2 vasodilatation, fig 7). The reduction in $\mathrm{MVO}_{2}$ following intracoronary bolus injection of high dose felodipine or nifedipine probably results from the potent negative inotropic properties of these agents, separate from the relaxing effect on the coronary smooth muscle cells. Using physiological oxygen supply:demand ratios as a reference, intracoronary administration of nifedipine clearly has more local effects on the coronary resistance vessels than intravenous administration of the same agent (figs 5 and 6).

\section{CONTRIBUTION OF COLLATERAL FLOW TO}

OXYGEN SUPPLY:DEMAND RATIO

In the prospectively studied group of patients the contribution of potential collaterals (including those that cannot be seen by coronary angiography) to coronary sinus blood flow was unknown. However, theoretically there is no reason to assume a different oxygen extraction ratio (and thus supply:demand ratio) in myocardium perfused via collaterals unless these collateral vessels induce significant arteriovenous shunting. As coronary venous oxygen tention remained constant during all interventions in the present study, there was no indication of significant intracoronary shunting.

\section{CONCLUSION}

Physiological regulation of coronary blood flow in awake and anaesthetised patients with CAD can be characterised by similar myocardial oxygen supply:demand ratios.

The myocardial oxygen supply:demand ratio and coronary microvascular vasodilating potency are potential tools for comparing coronary vasodilating drugs in clinical practice.

Intravenous administration of sodium nitroprusside, urapidil, and nifedipine in sufficient doses to control arterial blood pressure during surgical stress has limited coronary vasoactive effects in the majority of patients with CAD. The physiological coronary flow control system is still the major determinant of coronary flow in these patients.

Intracoronary high dose bolus injection of nifedipine and felodipine results in significant true vasodilatation.

The authors are grateful to Marjolein Porsius, research nurse, for her assistance and technical support during the experiments described in this study.

1 Broten TP, Feigl EO. Role of myocardial oxygen and carbon dioxide in coronary autoregulation. Am $\mathcal{f}$ Physio 1992;262:H1231-7.

2 Kuo L, Davis MJ, Chilian WM. Endothelium-dependent, flow-induced dilation of isolated coronary arterioles. $A m$ Physiol 1990;259:H1063-70.

3 Feigl EO, Van Winkle DM, Miyashiro JK. Cholinergic vasodilation of coronary resistance vessels in dogs, baboons and goats. Blood Vessels 1990;27:94-105.

4 Meininger GA, Davis MJ. Cellular mechanisms involved in the vascular myogenic response. Am $\mathcal{F}$ Physiol 1992; 263:H647-59.

5 Drake-Holland AJ, Laird JD, Noble MIM, Spaan JAE, Vergroesen I. Oxygen and coronary vascular resistance during autoregulation and metabolic vasodilatation in the during autoregulation and metabolic

6 De Fily DV, Chilian WM. Coronary microcirculation: autoregulation and metabolic control. Basic Res Cardiol autoregulation and

7 Eckenhoff JE, Hafkenschiel JH, Landmesser CM, Harmel $M$. Cardiac oxygen metabolism and control of the coronary circulation. Am $\mathcal{F}$ Physiol 1947;149:634-49.

8 Mohrman DE, Feigl EO. Competition between sympathetic vasoconstriction and metabolic vasodilation in the canine coronary circulation. Circulation 1978;42:79-86.

9 Vergroesen I, Noble MIM, Wieringa PA, Spaan JAE. Quantification of $\mathrm{O}_{2}$ consumption and arterial pressure 
as independent determinants of coronary flow. $A m \mathcal{F}$ Physiol 1987;252:H545-53.

10 Moffitt EA, Sethna DH. The coronary circulation and myocardial oxygenation in coronary artery disease: effects of anesthesia Anesth Analg 1986;65:395-410.

11 Harrison DG, Kurz MA, Quillen JE, Sellke FW, Mugge A Normal and pathophysiologic considerations of endothelial regulation of vascular tone and their relevance to nitrate therapy. Am $\mathcal{F}$ Cardiol 1992;70:11B-17B.

Barendse GAM Fiolet JWT, Dijkhuis JP. Myocardial metabolism and coronary sinus blood flow during coronary artery surgery: effects of nitroprusside and nifedipine. Am Heart $\mathcal{f} 1987$ 113:266-73.

13 Van Wezel HB, Bovill JG, Visser CA, Koolen JJ, Janse MJ, Myocardial metabolism, catecholamine artery , and left ventricular function during coronary Cardiothorac Anesthesiol 1987;1:408-17.

14 Van Der Stroom JG, Van Wezel HB, Vergroesen I, Kal JE, Koolen JJ, Dijkhuis JP, et al. Comparison of the effects of urapidil and sodium nitroprusside on haemodynamic state, myocardial metabolism and function in patients during coronary artery surgery. Br $\mathcal{F}$ Anaesth 1996;76: during $645-51$.

15 Koolen JJ, Van Wezel HB, Piek JJ, van Liebergen R, Swaan $A$, Visser CA. Effects of intracoronary felodipine versus nifedipine on left ventricular contractility and coronary sinus blood flow in stable angina pectoris. $\mathrm{Am} \mathrm{f}$ Cardiol 1994;74:730-2.

16 Van Wezel HB, Bovill JG, Koolen JJ, Patrick MR, Fiolet JWT, Van Der Stroom JG. Influence of glyceryl trinitrate and nifedipine on coronary sinus blood flow and global myocardial metabolism during coronary artery operation.

17 Mathey DG, Chatteriee K, Tyberg JV, Lekven J, Brundage $B$, Parmley WW. Coronary sinus reflux. A source of erro in the measurement of thermodilution coronary sinus flow. Circulation 1978;57:778-86.

18 Koberstein RC, Pittman DE, Klocke FJ. Right atria admixture in coronary venous blood. Am $\mathcal{F}$ Physiol 1969 216:513-35.

19 Ganz W, Tamura K, Marcus HS, Donoso R, Yoshida S, Swan HJC. Measurement of coronary sinus blood flow by continuous thermodilution in man. Circulation 1971, 44:181-95.

20 Feigl EO. Coronary physiology. Physiol Rev 1983;63:1-205.

21 Jones CJH, Kuo L, Davis MJ, Chilian WM. Myogenic and flow-dependent control mechanisms in the coronary microcirculation. Basic Res Cardiol 1993;88:2-10.

22 Kitamura K, Jorgensen CR, Gobel FL, Taylor HL, Wang Y. Hemodynamic correlates of myocardial oxygen consumption during upright exercise. $\mathcal{J}$ Appl Physiol 1972; 32:516-22. 